\title{
Plasma Torch Working Gas Selection Rationale for the Production Technology of Ultrapure White Corundum
}

\section{Viktorila Kison¹, Aleksander Mustafaev", and Vladimir Sukhomlinov²}

${ }^{1}$ Saint Petersburg Mining University, Saint Petersburg, 21st Line, 2, St. Petersburg, 199106, Russia

${ }^{2}$ Saint Petersburg State University, Ulyanovskaya, 3, St. Petersburg, 198504, Russia

ORCID:

Viktoriia Kison: http://orcid.org/0000-0003-2554-8526

\section{Abstract}

This paper presents the results of one of the stages in the development of a plasma technology for producing ultrapure white corundum. This technology involves the melting of alumina in a reactor under the influence of plasma. To create the plasma, a plasma-forming gas is needed; in other words, the plasma torch working gas. To implement this technology, the chosen working gas must meet certain requirements.

Corresponding Author:

Viktoriia Kison

kison.vika@mail.ru

Published: 5 April 2021

Publishing services provided by Knowledge E

(c) Viktoriia Kison et al. This article is distributed under the terms of the Creative Commons

Attribution License, which

permits unrestricted use and redistribution provided that the original author and source are credited.

Selection and Peer-review under the responsibility of the DonAgro Conference Committee. More precisely: 1) the gas should not form explosive or toxic compounds either with the reactor materials or the material of the electrodes; 2) it should not accelerate their erosion. An important requirement that a plasma torch working gas must have is minimal interaction with surrounding substances, even at high temperatures. This will reduce the likelihood of contamination of the melt with materials of the reactor itself. We consider using hydrogen, nitrogen and argon. Taking into account the requirements for the working gas, we opt for the mixture of nitrogen and argon at a concentration of $25 \div 30 \% \mathrm{~N}_{2}-70 \div 75 \%$ Ar.

Keywords: plasma torch, corundum, plasma technology, ultrapure materials

\section{Introduction}

Nowadays corundum (crystalline aluminum oxide) is used worldwide. Its purity level is essential for many of the fields of its application.It is especially vital for optical systems, microcircuits, and medical equipment. Producing ultrapure corundum also makes it possible to mine aluminum, including for the purposes of hydrogen energy.

There are two main industrial ways of producing electrocorundum: 1) in arc furnaces having a capacity of 5-7 MVA when melting with casting on a solid block, and 2) in furnaces having a capacity of 12.5-16.5 MVA when melting with the release of melting products in two tap holes [1-3]. Among the disadvantages of these methods 
are excessive pollution of the resulting corundum, high energy consumption, and low environmental friendliness of production.

The demand for pure white corundum is constantly growing in the global market these years.It requires the emergence of new technologies.

We claim that the plasma technology for producing ultrapure white corundum from alumina can be one of such technologies. This technology involves alumina melting under the influence of plasma in the reactor. To obtain the maximum purity of the resulting corundum two conditions are required: 1 ) the use of pure raw materials, and 2) minimizing the formation of impurities during the process.

This article provides evidence for using a plasma-forming gas in capacity of the working gas of the plasma torch.

\section{Materials and Methods}

At this stage of the development of a plasma technology for producing pure white corundum, a number of requirements are set for the feedstock, the installation itself, including its individual parts, such as a plasma torch, and a melting reactor, as well as for technological processes associated with the production of corundum.

To obtain ultrapure corundum, it is necessary to control the incoming impurities throughout the process. One of the sources of impurities is the plasma torch working gas -electrodesinteraction and plasma torch working gas - lining materials contact. We analyzed the physical and chemical properties of such interaction and its effect on the production process to choose an optimal working gas for the technology understudy.

\section{The Study of the Possibility of Using Various Gases}

Due to the high thermal conductivity and high specific enthalpy of plasma jets, hydrogen or nitrogen are used to solve the problems of heating and melting solids.

For the rationale of the plasma torch working gas, it is necessary to formulate the criteria by which the selection is conducted. They include:

1. high efficiency of energy exchange between a gas stream and a heated surface;

2. low erosion rate of the first layer of the tank inwall resulting from the interaction with the working gas of the plasma torch; 
3. Iow diffusion rate of the working gas molecules in the lining layers and low efficiency of the formation of caverns and cavities filled with gas in melting tank inwall, which lead to mechanical strength reduction;

4. absence of chemical reactions between the gas molecules (atoms) and melting tank inwall, that might result in forming harmful, hazardous, and poisonous substances and increasing the erosion rate of a reactor wall;

5. low cost per unit mass of the working fluid of the plasma torch.

In the process of heat transfer,the energy stored in the atomic fraction of plasma is released as it is transferred to the heated surface. The gas heat conductivity is of great importance since jet-to-surface heat transfer depends particularly on this parameter. The line graph in Figure 1 shows the dependence of the gases thermal conductivity (in $\mathrm{W} /(\mathrm{m} \cdot \mathrm{K}))$ on their temperature.

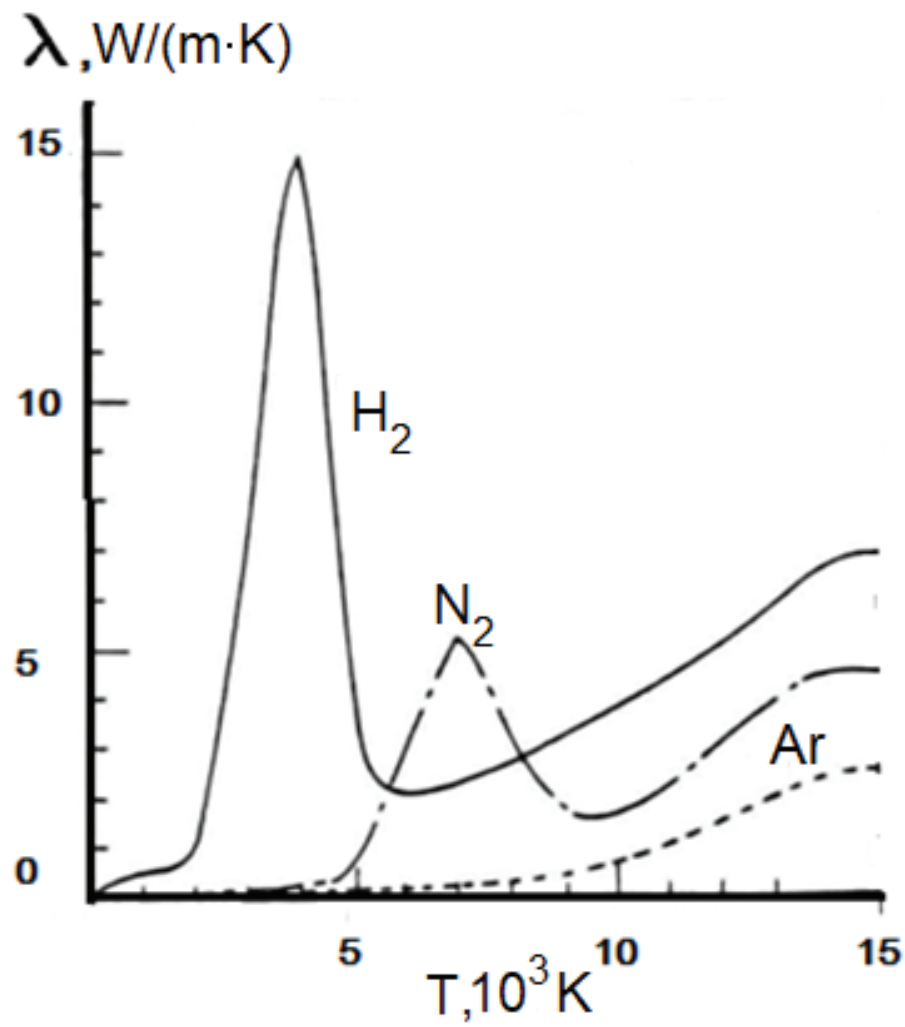

Figure 1: Thermal conductivity of working gases

We should note that air was immediately excluded from our consideration, because the contact of the planned materials for the reactor wall coating and the melt results in light volatile oxides evolution. This causes the coatings to accelerate dramatically in contrast with oxygen-free gases. 
The plasma on exit from the plasma torch can reach a temperature range of 8000 $10000 \mathrm{~K}$. When the jet interacts with the free surface of a liquid or solid phase, the flow undergoes compression (at high speed it becomes adiabatic), which should be taken into account when calculating heat transfer.

The heat transfer between the plasma and the melt through the spot in the vicinity of the plasma flow stagnation point can be estimated using the Nusselt number [4]. Further, the Nusselt number depends on the Rayleigh number (Ra), Reynolds number $(\mathrm{Re})$, and Prandtl number ( $\mathrm{Pr})$. This connection is determined by the type of convection (forced or natural), the type of flow (film, laminar or turbulent, subsonic or supersonic), etc. [5].

In the case of a plasma jet, with parameters close to equilibrium, one can use the well-known solution of the "flooded jet" problem, which gives spatial distributions of gas parameters when the jet flows through an opening into its own gas at rest [6]. The calculations show that under the considered conditions the plasma torch jet is turbulent, and the type of convective heat transfer is forced.

Bearing in mind the plasma torch efficiency, power, and jet velocity corresponding to a given power, we found out the following Nusselt numbers for the gases under discussion $-\mathrm{Nu}_{A r} \approx 40 ; \mathrm{Nu}_{2} \approx 11 ; \mathrm{Nu}_{H 2} \approx 10$. These results are in good agreement with the results of experiments conducted in [7-10].

Thus, due to higher thermal conductivity, specific enthalpy of molecular gases at high temperatures and heat transfer parameters, nitrogen and hydrogen are more efficient gases from the point of view of heating and further melting of alumina than argon. However, the plasma torch parameters for nitrogen and hydrogen will be different, since for the same energy supplied to the melt, the jet velocity of the plasma torch on nitrogen can be significantly (almost 10 times) lower than that of the plasma torch on hydrogen and 5-6 times lower than the plasma torch on argon. The reason for this is the low density of hydrogen compared to nitrogen at approximately the same specific enthalpy. Therefore, according to the first requirement listed at the beginning of this section (3), nitrogen is considered to be the most preferred.

The next selection criterion is the lack of interaction of the plasma torch working gas with the material of the reactor walls. If we use argon as a working gas of the plasma torch, no additional requirements are put forward on the outer lining layer (or coating of the outer layer), because this gas is chemically neutral, and the diffusion coefficient of argon atoms in a solid is negligible even at the considered high temperatures. 
If we use nitrogen, hydrogen, or a mixture of nitrogen with argon, the outer layer must meet some additional requirements. For example, it is undesirable to use carboncontaining materials for the outer layer of the lining due to the possibility of cyanide formation (with the possibility of further conversion to cyanides as a result of reactions with wear products of reactor units) in response to the synthesis reaction $2 \mathrm{C}+\mathrm{N}_{2}$ $\rightarrow 2 \mathrm{C}_{2} \mathrm{~N}_{2}$.

The reaction proceeds at high temperature in plasma especially effectively to form electronically and vibrational excited molecules with increased chemical activity. In an arc plasma, at high temperatures, the dissociation of water molecules with the formation of atomic hydrogen is possible. In the future, if atomic hydrogen interacts with nitrogen and carbon in a chain of reactions of methane formation and its reaction with nitrogen, it may lead to the emergencies of low hydrocyanic acid concentration in the reactor, which is notoriously poisonous. To avoid this, we suggest covering the the reactor walls with a thin layer of molybdenum, that will allow to use carbon-containing materials in the first layer.

The carbon surface is not chemically inert at a temperature of about $2000 \mathrm{~K}$. In the presence of water and oxygen vapors, various gases are formed on the surface of graphite-containing materials [11]. We used a mass spectrometer to analyze these gases and determine their mass numbers. Hence, we found out that $\mathrm{H}_{2}, \mathrm{CH}_{4}, \mathrm{CO}_{2}, \mathrm{CO}$ are the main gases that are formed on the surface of graphite under conditions close to those expected in the reactor. Notwithstanding, hydrogen is generated due to the water molecules dissociation on the surface of the carbon-containing material.

The aforesaid chemical reactions occur mainly on the surface of the first layer of the lining provided it is manufactured with the use of graphite-containing materials. The resultants are volatile gases, which association energy with the graphite surface is not strong. Therefore, these processes will cause surface erosion at a temperature of about $2000 \mathrm{~K}$. Moreover, this is applied not only to a nitrogen-containing, but also to any kind of atmosphere.

Thus, when we use nitrogen-containing gases as the plasma torch working fluid, we should either omit using carbon-containing materials for the first layer of the lining or provide it with a thin chemically neutral outer coating, for example, made of molybdenum, to avoid lowering the heat flux through the first layer. This will help to avoid ingress of material from the reactor walls, and eliminate the possibility of the melt crystallization on the reactor walls, which leads to heterogeneity of the obtained corundum.

The aforementioned note on the necessity of oxygen-free atmosphere in the reactor can be fully applied to molybdenum, which oxides are very volatile. 
Taking into account some excess pressure of the plasma torch jet, the atmosphere in the reactor will be inert with respect to molybdenum. That is, it will be anoxic or the amount of oxygen will be very small, insufficient to quickly reduce the resource.

It is also important to note the possibility of using a mixture of nitrogen and argon as the working gas of the plasma torch. It is common knowledge that increasing the capacity resource of plasmatrons is an urgent problem. It is mostly erosion of the electrodes of the plasma torch, in particular, the cathode, that limits the resource. According to [12], the fraction of nitrogen atoms in plasma of a mixture of argon and nitrogen sharply increases, that is associated with the transformation of the electron energy distribution function. Moreover, the maximum is observed at nitrogen concentration $25 \div 30 \%$.Furthermore, the emergence of a significant amount of atomic nitrogen leads to the phenomenon of the electrode surfaces nitriding, which facilitates their hardness and erosion properties improvement.

Thus, we expect that using the mixture of argon and nitrogen as a plasma-forming gas can increase the plasma torch resource in comparison with the use of pure argon and nitrogen.

When developing the design of a reactor for plasma melting of alumina, it is necessary to provide the possibility of the optimization of the melting process by allowing for the movement of the plasma torch jet along the surface of the melt, as well as a change in the inclination of the axis of the jet with respect to the normal line to this surface. This makes it necessary to use lubricants in the nodes to provide the appropriate movement. Bearing in mind high temperatures, it will be structurally difficult to ensure the tightness of the reactor in order to prevent the ingress of air through sealing. Therefore, we propose to increase pressure of the working gas of the plasma torch in the reactor using special valves

In addition, the upper limit of the operating temperature of most lubricants is about $500 \mathrm{~K}$ [13]. Given that a range of temperature for alumina melting is at $2300 \div 2400 \mathrm{~K}$, we need to focus on the upper values of the operating temperature range of lubricants. However, at these temperatures, the vapor pressure of most of engine oils increases by order of magnitude compared to normal conditions [13]. These circumstances can lead to the formation of an explosive mixture of oil, hydrogen and oxygen vapors if hydrogen is used as the working gas of the plasma torch.

Thus, we consider the mixture of nitrogen and argon to be the most preferred and the safest as the working gas for the alumina-melting reactor.

Finally, with regard to the last selection criterion, argon and nitrogen are more costeffective than hydrogen. 


\section{Conclusion}

Basing on the conducted analysis and the proposed requirements, we opt for the mixture of nitrogen and argon (presumably, in concentration $25 \div 30 \% \mathrm{~N}_{2}-70 \div 75 \% \mathrm{Ar}$ ) as the plasma torch working gas for the following reasons. 1) It has a higher efficiency of surface heating under the considered conditions compared to pure argon. 2) It has lower energy consumption for plasma maintenance than in pure nitrogen. 3) It has lower voltage of ignition and combustion of the plasma torch. Moreover it makes it possible to increase the plasma torch resource by means of nitriding of the plasma torch electrodes.

In the framework of the problem being solved it is undesirable to use hydrogen as a working gas of a plasma torch, because of its high chemical activity resulting in the formation of harmful and explosive substances, high permeability and diffusion coefficient in a solid and, thereby its accumulation in the lining layers with subsequent deterioration of its physical and mechanical properties (decrease in thermal conductivity and mechanical strength).

When using the mixture of nitrogen and argon as the working gas of the plasma torch and using carbon-containing materials as the first layer of the lining, it is necessary to coat the reactor walls with a molybdenum layer to prevent intensive formation of cyanide with further possible formation of cyanide compounds in reactions with impurities of wear products of the moving mechanical parts of the reactor (units, providing loading of alumina, orientation in the space of the plasma torch, etc.). Also, such a coating is favorable in terms of reducing pollution and heterogeneity of the resulting corundum.

At the next stages of the study, it will also be necessary to select the materials of the plasma torch electrodes to minimize erosion of the cathode and anode, establish the plasma torch operating modes, and then carry out test launches of the reactor.

\section{References}

[1] Vetyukov, M. M., Cyplakov, A. M. and Shkolnikov, S. N. (1987). Electrometallurgy of Aluminum and Magnesium. Moscow: Moscow Publisher, p. 320.

[2] Grjotheim, K. and Kvande, H. (1993). Introduction to Aluminum Electrolysis. Dusseldorf: Aluminum-Verlag, p. 243.

[3] Mincis, M. Y., Polyakov, P. V. and Sirazutdinov, G. A. (2001). Electrometallurgy of Aluminum. Novosibirsk: Nauka, p. 368.

[4] Boulos, M. I., et al. (1993). Fundamentals of Plasma Particle Momentum and Heat Transfer. In R. Suryanarayanan (Ed.), Plasma Spraying: Theory and Applications. 
Singapore: Word Scientific Publishing Co. Pte. Ltd., p. 308.

[5] Miheev, M. A. and Miheeva, I. M. (1977). Heat Transfer Basics. Moscow: Energiya, p. 345.

[6] Landau, L. D. and Lifshitz, E. M. (1986). Hydrodynamics. Theoretical Physics (vol. 4). Moscow: Nauka, p. 736.

[7] Huglen, R. and Kvande, H. (1994). Global Considerations of Aluminum Electrolysis on Energy and the Environment. Presented at Proc. of the 123rd TMS Annual Meeting on Light Metals February 27 - March 3, 1994, San Francisco, USA, Minerals, Metals \& Materials Soc, p. 373.

[8] Halmann, M., Frei, A. and Steinfeld, A. (2007). Carbothermal Reduction of Alumina: Thermochemical Equilibrium Calculations and Experimental Investigation. Energy, vol. 32, issue 12, p. 2420.

[9] Cox, J. H. and Pidgeon, L. M. (1963). An Investigation of the Aluminum-OxygenCarbon System. Canadian Journal of Chemistry, vol. 41, p. 671.

[10] Lacamera, A. F. (2002). Carbothermic Aluminum Production using Scrap Aluminum as a Coolant US Patent 6475260.

[11] Homich, V. A., et al. (2010). Modeling the Formation of Atomic Nitrogen in a Glow Discharge Plasma in a Nitrogen-Argon Mixture. Technical Physics Letters, vol. 36, issue 19, p. 91.

[12] CHihraj, E. V., et al. (2010). Investigation of the Interaction of Graphite with Reactive Gases. Presented at Proceeding of International Conference "Interaction of Hydrogen Isotopes with Structural Materials - IHISM'10" July 2010, Voronezh, Russia, Sarov: RFNC - All Russian Research Institute of Experimental Physics, p. 232.

[13] Anufriev, V. I. (2001). Handbook of a Mechanical Engineer (vol. 3). Moscow: Mashinostroenie p. 859. 